\title{
Surgical complication of undiagnosed idiopathic central sleep apnea: case report
}

\begin{abstract}
The presenting case is to report a case of undiagnosed idiopathic central sleep apnea that was presented in the course of a diagnostic laryngoscopy performed under general anesthesia. He presented to us with postoperative $\mathrm{CO} 2$ narcosis and convulsion and further evaluation identified idiopathic central sleep apnea as the etiology of this complication. The patient was treated by CPAP. It is of prime importance to consider central sleep apnea in every patient who is to take general anesthesia and has a recent history of weakness and daytime sleepiness.
\end{abstract}

Keywords: Idiopathic Central Sleep Apnea, ICSA, Obstructive Sleep Apnea, OSA, Continuous Positive Air Pressure, CPAP
Volume 10 Issue 3 - 2019

\author{
Mohammad Reza Golrokhian Sani,' \\ Nematollah Mokhtari Amirmajdi² \\ 'Department of Otolaryngology, Head \& Neck surgery, \\ Northern Ontario School of Medicine, Canada \\ ${ }^{2}$ Department of otolaryngology, Head \& Neck surgery, Mashhad \\ University of Medical Sciences, Iran
} Bay Regional Health and science Center, 980 Oliver Road, Thunder Bay, Ontario, Canada, Tel 807-632-6759, Email Golrokhianmd@gmail.com

Received: June 21, 2019 | Published: June 25, 2019

\section{Case report}

A 75-year-old man referred to my clinic (MRG) complaining of hoarseness for two months. He had a positive history of long duration of smoking. His phys- ical exam revealed a small lesion on the right true vocal cord. The patient was scheduled for direct laryngoscopy under general anesthesia and biopsy. He had a history of severe fatigue started one year prior to his admission. Preoperative evaluation did not reveal any significant cardio-pulmonary dysfunction. While his history was suspicious for sleep apnea, his physical exam showed normal posterior air space. We studied the posterior air space with endoscopy in supine position and it was normal. He was never admitted in the sleep clinic for assessment. He needed biopsy to be performed and sleep studies were postponed after biopsy. We asked for OSA post-op care. His procedure lasted only for twenty minutes without bleeding and respiratory distress. The patient transferred to recovery room when he was completely stable. He developed a $\mathrm{CO}_{2}$ narcosis in recovery room and got convulsion. He was intubated again and transferred to ICU for post-operative care. We tried to remove the tracheal tube in several occasions, each time we faced with elevation of his $\mathrm{CO}_{2}$ level, and he could not tolerate it. We performed a tracheotomy to reduce the chance of late complications. He was totally con- scious and had normal breathing when he was awake. He could walk around, but he needed CPAP when he was asleep. Cardiologic evaluations revealed narrowing in two coronary arteries and stent inserted. We continued with his post-op care. He could walk and do all of his movements, but he needed his CPAP at night. We removed the tracheotomy tube and continued with CPAP. His polysomnographic studies that was attempted at this time showed sleep apnea in the Rapid Eye Movement (REM) sleep. The patient was diagnosed as a case of idiopathic sleep apnea and his laryngeal pathologic report was a benign polyp. $\mathrm{He}$ continues with his normal life with the assistance of CPAP at night.

\section{Discussion}

We do still put the diagnosis of idiopathic sleep apnea on this case, because of a clear-cut etiologic factor could not be found. But as a reminder of looking for a possible causative factor that brings about a symptom free case of sleep apnea to flare up and show its clinical manifestations, we have to search for the pathophysiologic conditions during and after general anesthesia that enhances the clinical occurrence of sleep apnea, in our case in the shape of its complication with $\mathrm{CO}_{2}$ narcosis and convulsion.

Otolaryngologists are quite familiar with obstruction sleep apnea (OSAS), they have the same end result as idiopathic sleep apnea has. However, from the point of their symptoms and signs, they are quite different. Both obstructive sleep apnea and idiopathic central sleep apnea (ICSA) are common in that they have higher res- piratory distress index, but respiratory struggle is a prominent symptom in OSAS and patients with ICSA do not show struggle at inspiration. Their physical exam is also different in that the OSAS patients have the origin of their difficulty in their collapsible zone in their upper airway while patients with ICSA have a wide- open posterior air space, shown in their routine physical exam and fiber-optic examination in supine position. These two main differences make the differential diagnosis very easy.

The etiology and pathogenesis of ICSA is not completely discovered. The di- agnosis is based on exclusion of the other causes of CSA's. Patients are not usually obese. The symptoms include fragmented sleep, insomnia, witnessed apnea and some daytime sleepiness. Snoring is $\operatorname{not}^{1-3}$ as intrusive as in OSAS. On a long range the cardiovascular and general complications may be the same. ${ }^{4}$ Awake $\mathrm{paCO}_{2}$ levels tend to be low. ${ }^{5}$ The patients with ICSA tend to have a high hypercapnic response. ${ }^{6-8}$ Arousals cause a transient in- crease in ventilation and a decrease in $\mathrm{paCO}_{2}$. Polysomnographic studies usually show frequent isolated central apneas or runs. They occur in NREM sleep and mostly arise from stage 1 and 2 . Their treatment includes respiratory stimulants and CPAP as well as oxygen therapy. ${ }^{8} \mathrm{CPAP}$ has been used to treat ICSA. ${ }^{2,3,9,10}$ It probably works by stabilizing the upper airways and abolish- ing the upper airway resistance related arousals. It might also minimize $\mathrm{paCO}_{2}$ overshoots after an arousal. ${ }^{11}$ It has also been suggested that it might slightly increase the sleeping $\mathrm{paCO}_{2}$ in patients who are hypocapnic at baseline. Adaptive servo ventilation (ASV) might be a reasonable treatment strategy in selected cases. $^{12}$ 
Pathophysiologically, we depend on the American academy of sleep medicine, where an international classification of sleep disorders are agreed upon ${ }^{1-3}$ in their classification central sleep apneas are defined as follows: pattern

Primary (Idiopathic) central sleep apnea. Cheyne-stokes breathing

CSA due to high-altitude periodic breathing CSA due to drug or substances

Primary sleep apnea of infancy

According to above pathophysiologic background of CSA, our case may be exposed to one of the major categories listed above: CSA due to drug and sub- stances." Two main substances, ${ }^{13,14}$ that are usually used during the course of general anesthesia.The first group is the corner stone of most of the general anesthesia, respiratory depressants. Their untoward effect is treated by assisted respiration, while the patients' respiration is depressed. The second group of medications and substances being used during a general anesthesia is the so called muscle relaxants. Drug induced respiratory suppression may also affect as a high-altitude effect, but in either way this adverse effect is well-known to anesthesiologists and it is overcome by respiratory assistance. The effect of muscle relaxants may stay longer and need more sustained respiratory assistance. Any negligence to consider this causative factor may be a predisposing factor.

The review of literature, so far has not pointed to any clear result that the general anesthesia has a direct effect on flaring up ICSA. ${ }^{13}$ But the magnif- icent article written by H.V. Genzwuerker and J Meinhardt, ${ }^{14}$ defines many interrelations between this clinical entity with anesthesia. Apart from what they discussed in relation to different anesthetics and drugs that we have to be cautious about, we coat directly to their statement about muscle relaxants and how we have to manage their harmful effect on cases such as ICSA. "The oropharyngeal muscles are especially sensitive to non-depolarizing mus- cle relaxing substances. Even small doses as used for priming can lead to air- way obstruction. This also pertains to a residual effect of muscle relaxants in the postoperative phase that may lead to respiratory distress after extubation. "They advised the use of antagonists in this case if any sign of partial neuromuscular blockade is present.

\section{Conclusion}

By reporting a case of ICSA that presented in the course of postoperative laryn- goscopy in recovery room, by $\mathrm{CO}_{2}$ narcosis and convulsion, and reviewing the literature we point to the possible effect of muscle relaxants in the post-operative course of any general anesthesia. Proper management of this complication is done accordingly.

\section{Conflict of interest}

There is no conflict of interest in this case report

\section{Source of funding}

There is no other source for funding of this article. Author asked patient for publishing in article anonymous. Data and materials are available.

\section{References}

1. Rutherford R, Rankin F, Wong B, etal. Hypocapnia and increased ventilatory responsiveness in patients with idiopathic central sleep apnea. Am J Respir Crit Care Med.1995;152(6 Pt 1):1950-1955.

2. Muza Rexford T. Central sleep apnoea-a clinical review. J Thorac Dis. 2015;7(5):930-937.

3. Sulivan CE, Kozar LF, Murphy E, et al.Primaryrole of respiratory afferents in sustaining breathing rhythm. J Appl Physiol Respir Environ Exerc Physiol. 1978;45(1):11-17.

4. Berssenbrugge A, DEmpsy J, Iber C, et al. Mechanisms of hypoxia-induced periodic breathing during sleep in humans. J Physiol. 1983;343:507-524.

5. White DP. Occlusion pressure and ventilation during sleep in normal humans. Journal of Applied Physiology. 1986;61(4):1279-1287.

6. Bradely TD, Nicholas WT, Rutherford R, et al. Clinical and physiologic heterogenety of the central sleep apnea. Am Rev Respir Dis. 1986;134(2):217-221.

7. Xie A,Wong B, Phillipson EA. Interaction of hyperventilation and arousal in the patho- genesis of idiopathic central sleep apnea. Am J Respir Crit Care Med. 1994;150(2):489-495.

8. Badr MS, Grossman JF, Weber SA. Treatment of refractory sleep apnea with supplemental carbon dioxide. Am J Respir Crit Care Med. 1994;150(2):561-564.

9. Issa FG, Sullivan CE. Reversal of central sleep apnea using nasal CAPA. Chest. 1986;90(2):165-171.

10. Douglas NJ, White DP, Pickett CK, et al. Respiration during sleep in normal man. Thorax. 1982;37(11):840-844.

11. Gould GA, Gugger M, Molloy J, et al. Breathing pattern and eye movement density during REM sleep in humans. Am Rev Respir Dis. 1988;138(4):874-877.

12. Alexa A, Mansukhani MP, Gali B, et al. Primary central sleep apnea and anesthesia: a retrospective case series. Can J Anaesth. 2018;65(8):884892.

13. Genzwuerker HV, Meinhardt J. Perioperative risks and their management in patients with sleep-related breathing disorders. GMS Curr Top Otorhinolaryngol Head Neck Surg. 2006;5. 